Reply

DEAR SIRS

I am grateful for the opportunity to explain some examination procedures.

It is intended that if possible, no candidate for the MRCPsych examination should be examined by someone with whom they have worked or trained, nor at the same centre or by the same examiner as on previous attempts. In respect of the clinical examinations therefore, those candidates most difficult to place are those with previous attempts.

In order to organise the clinical examination, we need to know all eligible candidates. Although the closing date is sometime before the examination, a considerable number of candidates, tutors and sponsors fail to complete forms correctly or to include necessary documentation. The responsible member of the examinations staff has to pursue these deficiencies and usually information is only complete three or four weeks before the examination date. It is only then that the complicated business of planning the timetable can begin; candidates are informed of date and venue as soon as possible.

With regard to the results, the Examinations Sub-Committee (ESC) feels that, in view of the importance of the examination, every candidate deserves to have the results scrutinised and any queries (whether from candidate, organiser or examiner), investigated. All results for Part I and Part II are scrutinised by the ESC, and, in Part II, by the Court of Electors. Where there is any doubt or disagreement, papers are re-marked by a third examiner. The performance of all candidates on their last attempt is examined in detail. This all takes time, especially as members of the ESC and examiners are not seconded to examine but are in psychiatric practice, as I believe appropriate.

I am fully aware of the anxieties of candidates and there are ways of speeding up procedures which we could consider. We could reject all candidates whose documentation is inaccurate or incomplete; we could be less scrupulous in checking queries and results. I would be reluctant to pursue either course.

We are, however, looking at the forms to see if they can be made clearer to candidates and tutors. Although the number of candidates entering for the examinations has increased sharply, there has not been a commensurate increase in examinations staff, who are under very great pressure. We are considering whether to propose an increase in staff, but are conscious that to do so, given that the examination must break even financially, might mean an increase in the entry fee.

Dr Bende and her fellow candidates can be sure that we are aware of their concerns, and will continue to seek improvements. I hope that this explanation has been helpful.

Sheila MaNN

Chief Examiner

\section{Out-patient non-attenders}

DeAr Sirs

In Dr Baggaley's article 'improving attendance for new psychiatric out-patient referrals' (Psychiatric Bulletin, June 1993, 17, 347-348), while the attendance rate for appointments made in the experimental group was $97 \%$, the overall attendance rate for those originally referred fell from $72 \%$ to $63 \%$. Many factors contribute to non-attendance but it should be assumed that referrers consider referral necessary and appropriate. The characteristics of the extra non-attenders with this method of appointment allocation are unknown though the author suggests their diagnoses may be similar to other non-attenders.

Surveys comparing attenders with non-attenders have shown varying results and Frankel et al (1989) concluded that the form of service delivery is more important than patient factors in determining nonattendance. Diagnosis did not differentiate between attenders and non-attenders according to Shah \& Lynch's survey (1990) and neither did symptom severity (Thapar \& Ghosh, 1991). The extra nonattenders are therefore likely to be a heterogeneous group and may contain a severely ill sub-group for whom being required to contact the department for an appointment tipped the balance into non-attendance.

While I agree that improving efficiency by reducing non-attendance is worthwhile, if it results in fewer of the referrals being assessed and treated any increase in suffering caused is of major importance unless, as Dr Baggaley suggests, an alternative method of service provision could be offered to non-attenders.

Middlewood Hospital

C. W. Rusius

Sheffield S6 1TP

\section{References}

Frankel, S., Farrow, A.\& West, R.(1989) Non-attendance or non-invitation? A case control study of failed outpatient appointments. British Medical Journal, 298, 1343-1345.

SHAH, A. K. \& LYNCH, S. (1990) Characteristics of patients in a psychiatric follow-up clinic. Psychiatric Bulletin, 14, 153-154.

Thapar, A. \& Ghosh, A. (1991) Non-attendance at a psychiatric clinic. Psychiatric Bulletin, 15, 205-207.

\section{DeAr Sirs}

Dr Baggaley states that non attenders represent a group that either do not need specialised psychiatric intervention or that out-patient appointments are 